\title{
Factors Influencing Aggression Levels in Root Vole Populations under the Effect of Food Supply and Predation
}

\author{
Haiyan Nie, ${ }^{1}$ Mingcan Yao, ${ }^{1}$ and Jike Liu ${ }^{2}$ \\ ${ }^{1}$ College of Life Science and Technology, Central South University of Forestry and Technology, Changsha 410004, China \\ ${ }^{2}$ College of Life Sciences, Zhejiang University, Hang Zhou, Zhejiang 310029, China \\ Correspondence should be addressed to Haiyan Nie; niehaiyan@126.com
}

Received 27 June 2013; Accepted 13 August 2013

Academic Editors: C. Jarnevich, M. Perez-Fernandez, and D. Pimentel

Copyright (c) 2013 Haiyan Nie et al. This is an open access article distributed under the Creative Commons Attribution License, which permits unrestricted use, distribution, and reproduction in any medium, provided the original work is properly cited.

\begin{abstract}
Which factor determines animal aggressivity? Wynn-Edwards proposed the hypothesis that aggressive level increases with population density; Adams and Mesterton-Gibbons proposed the hypothesis that body weight is an indicator of animal aggressivity; however, Smith and Price hypothesized that aggression level varied with external conditions; that is, the population lived in the most unfavorable environment demonstrated the highest average aggression level, and the population that lived under the most favorable external conditions demonstrated the lowest average aggression level. In this paper, we tested these three hypotheses by manipulating enclosed root vole (Microtus oeconomus) populations under different food and predation treatments and observed their aggressive behavior. Aggressive behavior was measured by matching mice in a neutral arena. The experimental results supported Smith and Price's hypothesis and Adams and Mesterton-Gibbons's hypothesis; however, they did not support WynnEdwards' hypothesis. Moreover, we found that reproductively active individuals were more aggressive. We concluded that the growth of population density did not cause or otherwise bring about increased aggressive behavior of root voles, but the external factors (predation and food supply) and physical factors (body weight and reproductive condition) were significantly correlated with aggression levels in a root vole population.
\end{abstract}

\section{Introduction}

Wynn-Edwards' hypothesis proposed that animals adjust their population density to available resources through social behavior and that aggressive behavior increases with population density [1]. Some subsequent field experiments supported this hypothesis [2-8]. However, Vale et al. demonstrated another aspect of the relationship between agonistic behavior and population density [9]. They showed that with different genetic strains of mice at equal densities, one strain was aggressive and the other was not. Lidicker examined patterns of wounding in population of California vole (Microtus californicus, Peale, 1848) and concluded that season was more important than density in determining levels of aggression [10].

Aggression levels of fluctuating arvicoline populations have been assessed by observation of agonistic behavior during dyadic encounters in neutral arenas for five species: meadow vole Microtus pennsylvanicus (Ord, 1815) [5, 1113], prairie vole Microtus ochrogaster (Wagner, 1842) [12, 13], beach vole Microtus breweri (Baird, 1858) [14], redbacked vole Clethrionomys gapperi (Vigors, 1830) [15], and Townsend's vole Microtus townsendii (Bachman, 1839) [16]. Only Krebs found evidence that aggression level increased with population density [5]. In general, the relationship between agonistic behavior and population density remains uncertain.

Smith and Price proposed the hypothesis that aggression level varied with external conditions, that is, the population lived in the most unfavorable environment demonstrated the highest average aggression level, and the population that lived under the most favorable external conditions demonstrated the lowest average aggression level [17]. Smith and Price analyzed population aggression by ESS game model, which predicts that when the value of the resource is greater, winning a "war" is more important for foraging food, 
defending territory, protecting offspring, and so forth, and the proportion of "hawks" in the population is higher [17].

However, Adams and Mesterton-Gibbons proposed the body weight assessment hypothesis; that is, body weight is an indicator of strength [18]. Each animal compares its own strength to that of its opponent and withdraws when it judges itself to be the probable loser. For weaker opponents, strong aggressiveness may mean wasting energy needlessly against much stronger opponents, who would win in any case.

During the course of studying the effects of food supply, predation, and the interaction between them on the population dynamics of root voles, Microtus oeconomus (Pallas, 1776), by adopting factorial experiments in field enclosures [19], we obtained data of aggressive behavior from root vole populations. In this paper, we analyzed the relationship between aggression level and population density, weight, and external conditions in root vole populations to test the above three hypotheses.

\section{Materials and Methods}

2.1. Study Area. The fieldwork was conducted from May to October in 1990 at Haibei Alpine Meadow Ecosystem Research Station of Chinese Academy of Sciences. The research station is located at northeast of Tibet, in a large valley oriented NW-SE surrounded on all sides by the Qilian Mountains with N latitude $37^{\circ} 29^{\prime} \sim 37^{\circ} 45^{\prime}$ and E longitude $101^{\circ} 12^{\prime} \sim 101^{\circ} 23^{\prime}$. The average altitude of mountain area is $4000 \mathrm{~m}$ a. s. 1 . and $2900 \sim 3500 \mathrm{~m}$ in the valley. The Datong River passes the south of the area. The landscape is characterized by large mountain ranges with steep valleys and gorges, interspersed with relatively level and wide intermountain grassland basins. The natural conditions, vegetation, and soil structure of the study area has been reported elsewhere [20].

The study site was located at an old field of Elymus nutans meadow, a secondary vegetation type after the original one had been destroyed. The majority of plants were Elymus nutans, Poa sp., Thalictrum alpinum, Kobresia humilis, Potentilla fruticosa, and so forth. The soil was loose, moist, and fertile with a dense and high plant leaf layer, which was the natural habitat for root voles. The dominant plant, $E$. nutans, was soft and nutritive and preferred strongly by root voles [21]. Besides root voles, other rodents inhabited the $E$. nutans meadows, such as zokor Myospalax baileyi (Thomas, 1911), pikas Ochotona cansus (Lyon, 1907), and O. curzoniae (Hodgson, 1858).

The avian and mammalian predators observed in the study area were the falcon Falco tinnunculus (Linnaeus, 1758), buzzard Buteo hemilasius (Temminck and Schlegel, 1844), weasels Mustela altaica (Pallas, 1811), M. eversmanni (Lesson, 1827), the wolf Canis lupus (Linnaeus, 1758), foxes Vulpes vulpes (Linnaeus, 1758), and V. ferrilatus (Hodgson, 1842). The dominant species among them were the buzzard, the falcon, and the weasels.

We constructed the enclosures with $2 \times 1 \mathrm{~m} \delta 0.5$ galvanized steel panels that extended $0.5 \mathrm{~m}$ below and $1 \mathrm{~m}$ above ground. Four treatments $(2 \times 2$ factorial design $)$ with two replicates were designed as follows: no predator, food supplemented $(-\mathrm{P},+\mathrm{F})$; predator access, food supplemented $(+\mathrm{P},+\mathrm{F})$; no-predator, nonsupplemented $(-\mathrm{P},-\mathrm{F})$; the control, predator access, nonsupplemented $(+\mathrm{P},-\mathrm{F})$. Within each enclosure, 42 trapping stations were staked in a $5 \times 7 \mathrm{~m}$ array. A wooden cage trap was placed at each trapping station, and 3 trapping cages were placed in each removal area. There were a total of 45 cages in every enclosure. The $-\mathrm{P},+\mathrm{F}$, and $-\mathrm{P},-\mathrm{F}$ enclosures were covered by fishing netting with a $3 \times 3 \mathrm{~cm}$ grid to prevent access by avian predators and the roof of the net was kept in place with a $\Phi 10 \times 250 \mathrm{~cm}$ pillar. The $+\mathrm{P},+\mathrm{F}$, and $+\mathrm{P},-\mathrm{F}$ enclosures were not covered with netting and had a series of low panels ( $0.30 \mathrm{~m}$ high) every $10 \mathrm{~m}$ except on sides shared with no-predator enclosures. Thus predators could easily enter these enclosures. Live traps were set all along outside the enclosures with low panels to detect escapees.

Supplemental food was granulated rabbit chow of TK10 type (made in Shanghai Feed Processing Plant), a high quality food on which microtine animals grow and reproduce well [21]. In $+\mathrm{P},+\mathrm{F}$, and $-\mathrm{P},+\mathrm{F}$ enclosures, food were kept in $500 \mathrm{~mL}$ glass jars, which were placed near every oddnumbered trap station in every row. There were 22 food jars in every enclosure and food was replenished weekly to ensure freshness and availability.

2.2. Population Density. After removal of the original resident root voles and nontarget species, five pairs of root voles from a laboratory colony were randomly assigned as population founders in each enclosure, which represented a moderate density compared to the natural population around the study area. The founder voles were nonsiblings of 3-5 months old and born in a laboratory. The animals had 1-2 weeks to become accustomed to the enclosures before trapping began [19].

There were three trapping days every two weeks in a trapping session. At dusk the day before a trapping session, the traps were set open, bedded with clean cotton, and baited with cracked corn. We examined the cages once every two hours each day during every trapping session. All cages were covered with hardboards of $2 \mathrm{~cm}$ thickness to reduce trap mortality caused by high temperature and were closed between trapping sessions. None of the animals died in the traps during the trapping sessions.

Upon first capture, each animal was marked with a numbered aluminum Style 1005-1s Monel ear tag produced by the National Band \& Tag Company. The whole marking procedure followed the Act on Animal Experimentation and Management released by the Ministry of Science and Technology of the People's Republic of China in 1988. We did not punch holes in the ears of animals but only clipped the tags onto their ears. The whole marking procedure did not appear to cause any distress or discomfort to the animals. The recaptured individuals were released at the point of capture after the following data were recorded: tag number, sex, weight, station number, reproductive condition, and general condition. Male reproductive condition could be determined by the size of scrotum and the location of testis, and the individuals with enlarged scrotum and descended testis were reproductively active. Whether a female was pregnant or 
lactating could be judged by the width of vaginal opening and the prominence of the nipples [22].

We classified root voles into two age classes based on size [23]: males $>25 \mathrm{~g}$ and females $>22 \mathrm{~g}$ were adults; others were juveniles. Population densities for every enclosure within each trapping session were estimated separately using the jackknife estimator for model Mh (including heterogeneity in capture rates) in the program CAPTURE [24].

2.3. Aggressive Behavior Testing. Aggression of adult rodent is strongly influenced by food quality during early developmental periods [25]. In the current study, population founders were fed with food of equal quality during infancy and had never been utilized for aggressive behavior tests. Aggressive behavior tests were conducted (1) 5 weeks after the founders had been placed in the enclosures, (2) when the number of individuals in each enclosure had reached a fair size, and (3) when there were adequate numbers of individuals for behavioral observation. Individuals selected for aggressive behavior testing were born in the enclosure.

It is difficult to accurately test the aggression levels of small mammals directly in the field [26], so our aggression tests were conducted in the behavior laboratory near the enclosure. The apparatus for aggressive behavior testing was a glass aquarium partitioned by a movable wooden board at the center. The box was cushioned with a $1 \mathrm{~cm}$ layer of saw dust and crushed corn. The box was placed in a dark room in the laboratory. A $40 \mathrm{w}$ fluorescent lamp was suspended about $1 \mathrm{~m}$ above the box. The observer watched and recorded aggression behavior through a hole in a green curtain hung $50 \mathrm{~cm}$ distance from the box.

Every individual was observed no more than twice within a trapping period and was tested only against others from the same enclosure. The encounters were different every time. The period between two observations was 30 minutes. Before lifting the partition board, 3 minutes were given for root voles to acclimatize to the new space. The board was then raised and the voles watched for ten minutes. The root voles were put back into cages after observation and fed with adequate crushed corns and water and then taken back to the sites where they had been trapped within 1-2 hours. The glass box was cleaned with soap water to eliminate odor gathered in the box.

The following behaviors were recorded following the classification standard of Hofmann et al. [12] as follows: (1) threat-raising forelegs and stretching head, shaking forelegs, teeth baring, and screaming; (2) upright-hind legs standing straight, body extending, and the two individuals facing each other closely during mutual upright; (3) lungeone individual stretching head toward the other, leaping from ground, attacking, and biting each other; (4) boxingthe upright individual striking head and shoulders of the other one; (5) wrestle-this behavior occurred rapidly and it was difficult to tell the launcher; (6) chase-one individual pursuing the other, often ended with one jumping on to the other's rear violently; (7) retreat-one individual fleeing away from the approaching or attacking individual; (8) approachone individual moving toward the other to a distance shorter than $5 \mathrm{~cm}$. Agonistic behavior 1 to 7 occurred frequently when both individuals were within approach distance, among which threat, lunge, and chase were initiative and nondefensive, or obviously aggressive. Therefore, the total number of threat, lunge, and chase was calculated as to stand for the relative aggression level of dyadic encounters and was defined as an aggression count [27].

2.4. Game Model. We used ESS (Evolutionary Stable Strategy) game models [28] to analyze the aggressive behavior of root voles. An ESS is a state of game dynamics where, in a very large population of competitors, another mutant strategy cannot successfully enter the population to disturb the existing dynamic, which in itself is population mix dependent. In the ESS model, a root vole population consists of hawks and doves. Let $p$ be the proportion of hawks in a population and $(1-p)$ the proportion of doves. If an animal won a contest, the benefit is $V$ units. If an animal incurred a serious injury, the cost is $W$ units. And if it is involved in a long display, the cost is $T$ units. According to Parker, $p=V / W$, or in other words, the greater the value of the resource, the higher the proportion of hawks. Conversely, the greater the cost of injury, the greater the proportion of the dove [28].

Among the agonistic behavior sequences recorded in the root vole population, lunge and chase were initiative and nondefensive, or obviously aggressive, so the individual which exhibited these two behaviours in a dyadic encounter was defined as "a hawk," otherwise, "a dove."

2.5. Statistical Analysis. Linear correlation coefficient between body weight and aggression level was calculated in order to determine the relation between individual size and its aggression level; correlation coefficient between aggression counts and population density was calculated by Spearman rank correlation analysis in order to determine the relation between aggression level and population density.

Kruskal-Wallis $H$-test was used to analyze the difference between average aggression levels under different treatments and also used to analyze aggression difference between males and females under different treatments. Difference between average aggression counts of reproductive individuals and non-reproductive individuals was analyzed by $t$-test. Independent effects and interaction of food and predation on aggressiveness of root vole populations under different treatment were analyzed by two-way ANOVAs.

\section{Results}

3.1. Aggression Level and Population Density. We marked and recaptured root vole populations under four treatments for 20 trapping sessions in total [19]. There was no significant linear regression between aggression counts and population density (Figure 1). According to the results of a Spearman rank correlation analysis, correlation coefficients between aggression counts and population density under all four treatments were not significant $(-\mathrm{P},+\mathrm{F}: r=-0.237, n=18$, $P=0.328$; $+\mathrm{P},+\mathrm{F}: r=-0.329, n=20, P=0.151$; 
TABLE 1: $H$-test of Kruskal-Wallis for aggression levels of root vole populations under different treatments.

\begin{tabular}{|c|c|c|c|c|c|c|c|c|}
\hline \multirow[b]{2}{*}{ Treatment } & \multicolumn{2}{|c|}{$+\mathrm{P},-\mathrm{F}$} & \multicolumn{2}{|c|}{$-\mathrm{P},+\mathrm{F}$} & \multicolumn{2}{|c|}{$-\mathrm{P},-\mathrm{F}$} & \multicolumn{2}{|c|}{$+\mathrm{P},-\mathrm{F}$} \\
\hline & $\begin{array}{c}\text { Experiment } \\
\text { data }\end{array}$ & Rank & $\begin{array}{l}\text { Experiment } \\
\text { data }\end{array}$ & Rank & $\begin{array}{c}\text { Experiment } \\
\text { data }\end{array}$ & Rank & $\begin{array}{c}\text { Experiment } \\
\text { data }\end{array}$ & Rank \\
\hline \multirow{20}{*}{$\begin{array}{l}\text { Aggression } \\
\text { accounts }\end{array}$} & 3.00 & 4.00 & 32.00 & 41.00 & 65.00 & 49.00 & 36.00 & 45.00 \\
\hline & 25.00 & 37.50 & 53.00 & 47.00 & 60.00 & 48.00 & 35.00 & 43.50 \\
\hline & 20.00 & 30.50 & 13.00 & 19.50 & 78.00 & 51.00 & 74.00 & 50.00 \\
\hline & 2.00 & 3.00 & 25.00 & 37.50 & 25.00 & 37.50 & 33.00 & 42.00 \\
\hline & 5.00 & 6.00 & 11.00 & 16.00 & 24.00 & 35.00 & 37.00 & 46.00 \\
\hline & 1.00 & 2.00 & 35.00 & 43.50 & 21.00 & 32.00 & & \\
\hline & 13.00 & 19.50 & 10.00 & 14.00 & 22.00 & 33.00 & & \\
\hline & 8.00 & 10.50 & 14.00 & 21.50 & 23.00 & 34.00 & & \\
\hline & 7.00 & 8.50 & 16.00 & 25.50 & 26.00 & 40.00 & & \\
\hline & 6.00 & 7.00 & 16.00 & 25.50 & & & & \\
\hline & 25.00 & 37.50 & 7.00 & 8.50 & & & & \\
\hline & 90.00 & 52.00 & 15.00 & 23.50 & & & & \\
\hline & 10.00 & 14.00 & 12.00 & 17.50 & & & & \\
\hline & 0.00 & 1.00 & 10.00 & 14.00 & & & & \\
\hline & 12.00 & 17.50 & 18.00 & 28.00 & & & & \\
\hline & 4.00 & 5.00 & 19.00 & 29.00 & & & & \\
\hline & 8.00 & 10.50 & 20.00 & 30.50 & & & & \\
\hline & 9.00 & 12.00 & 17.00 & 27.00 & & & & \\
\hline & 15.00 & 23.50 & & & & & & \\
\hline & 14.00 & 21.50 & & & & & & \\
\hline$R_{i}=$ & 323.0 & & 469. & & 359.5 & & 220. & \\
\hline
\end{tabular}

$R_{i}$ is the sum of sample rank under $i$ treatment.

$-\mathrm{P},+\mathrm{F}$ : no predator, food-supplemented enclosures.

$+\mathrm{P},+\mathrm{F}$ : predator access, food-supplemented enclosures.

-P, -F: no predator, nonsupplemented enclosures.

$+\mathrm{P},-\mathrm{F}$ : predator access, nonsupplemented enclosures, the control.

$-\mathrm{P},-\mathrm{F}: r=-0.183, n=9, P=0.606 ;+\mathrm{P},-\mathrm{F}: r=-0.112$, $n=5, P=0.823)$.

3.2. Food, Predation, and Aggression Level. The difference between average aggression levels under different treatments was significant $(H=24.12, \mathrm{df}=3, P<0.001)$ according to the Kruskal-Wallis $H$-test (Table 1 ).

3.3. Sex and Aggression Level. After observing 35 dyadic encounters between males and females, we found extremely weak aggression between different sexes, which could be neglected in the aggressive behavior analysis. Therefore, only the aggressive behavior between the same sex dyads was analyzed in this paper.

The difference of aggression level between males and females under different treatments was inconsistent (Figure 2). The aggression level of males was significantly higher than that of females in $-\mathrm{P},-\mathrm{F}$, and $+\mathrm{P},-\mathrm{F}$ population (the control), but the aggression level of females was significantly higher than that of males in $+\mathrm{P},+\mathrm{F}$ according to $H$-test $(+\mathrm{P},+\mathrm{F}: H=5.023$, df $=1, P<0.025 ;-\mathrm{P},-\mathrm{F}$ : $H=14.438, \mathrm{df}=1, P<0.005 ;+\mathrm{P},-\mathrm{F}: H=6.818, \mathrm{df}=1$, $P<0.01)$. However, the difference of aggression level between males and females was not significant in $-\mathrm{P},+\mathrm{F}$ population $(H=2.029$, $\mathrm{df}=1, P<0.25)$.

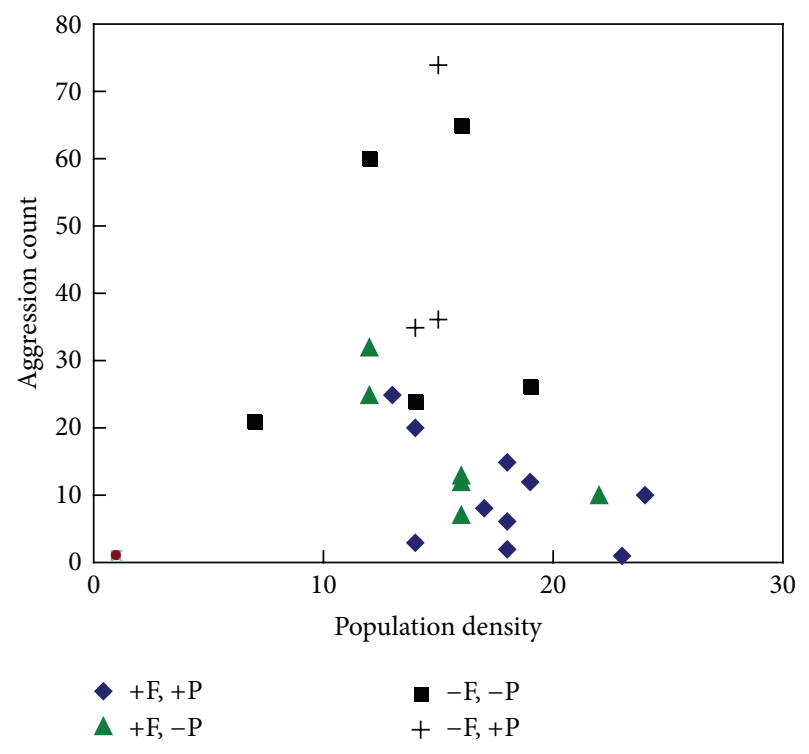

FIGURE 1: Aggression level and population density.

3.4. Reproductive Activity and Aggression Level. Individuals that were reproductively active showed higher incidences of aggressive acts than nonreproductively active individuals. 


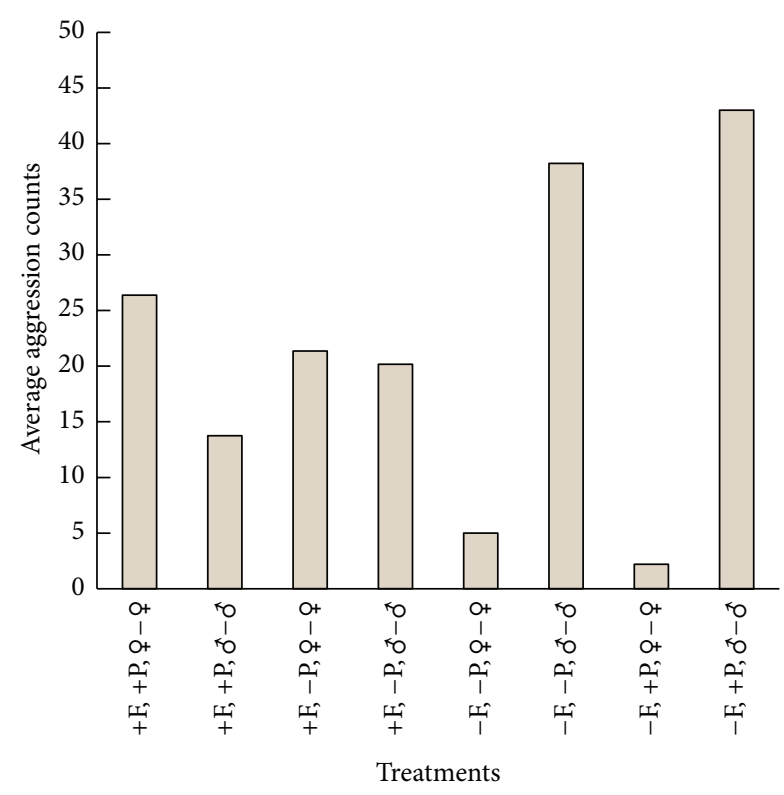

FIGURE 2: Difference of aggression level between males and females.

Reproductively active voles, especially lactating females, were evidently more aggressive, usually attacking the opponent to escape in a hurry. The difference between the aggression counts of reproductive individuals and those of nonreproductive individuals was found to be significant $(t=$ $11.885, \mathrm{df}=50, P=0.0026)$.

3.5. Body Weight and Aggression Level. Heavy voles showed high incidences of acts of aggression. The smaller one invariably gives up first. The heavier individual in a dyadic encounter usually became the dominant, and the smaller one became the subordinate. Body weight was significantly positively correlated with aggression counts $(r=0.375737$, $n=52, P=0.01$ ).

\subsection{Aggressive Behavior Strategies under Different Treatments.} The aggressive behavior pattern of root voles under different treatments (Table 2) was consistent with the prediction from an ESS hawk-dove model; that is, the proportion of "hawks" in root vole populations under unfavorable conditions $(+\mathrm{P}$, $-\mathrm{F}$ ) was much higher than that of root vole populations under favorable conditions $(-\mathrm{P},+\mathrm{F})$, and the proportions of "hawks" were at intermediate level under mediate environments $(-\mathrm{P}$, $-\mathrm{F} ;+\mathrm{P},+\mathrm{F})$. The aggressiveness of root vole populations under different treatment was different significantly $(F=79.909$, $n=20, P=0.01$ ).

\section{Discussion}

The experimental results supported Smith and Price's hypothesis and Adams and Mesterton-Gibbons's hypothesis; however, did not support Wynn-Edwards' hypothesis. Moreover, we found that reproductively active individuals were more aggressive.
TABLE 2: Proportion of hawks in the populations of root voles under different treatments.

\begin{tabular}{lcccc}
\hline Treatments & $-\mathrm{P},+\mathrm{F}$ & $+\mathrm{P},+\mathrm{F}$ & $-\mathrm{P},-\mathrm{F}$ & $+\mathrm{P},-\mathrm{F}$ \\
\hline Proportion of hawks & 0.17 & 0.18 & 0.33 & 0.40 \\
\hline
\end{tabular}

In our factorial experiment, body weight was significantly positively correlated with aggression counts, with heavier and reproductively active root voles showing significantly higher incidences of aggressive acts $(r=0.376, n=52, P=0.01)$, which supported Adams and Mesterton-Gibbons' hypothesis.

The conventional agonistic behavior of root voles was ritualized noninjurious behavior, which was consistent with the conclusion of Smith and Price [17] and Lendrem [29]. An ESS is always a mix of hawks and doves [17]. ESS game model predicts that when the value of the resource is greater, the proportion of "hawks" in the population is higher. Our experimental results supported this hypothesis. Under the most unfavorable conditions $(+\mathrm{P},-\mathrm{F})$, when resources are most valuable, winning a "war" is most important for foraging food, defending territory, protecting offspring, and so forth, and hence the highest proportion of "hawks" in the population; on the other hand, under the most favorable conditions $(-\mathrm{P},+\mathrm{F})$, the lowest proportion of "hawks" in the population (Table 2) and the difference were significant.

The difference in the aggression counts between reproductively active individuals and those of non-reproductively active individuals was found to be significant $(t=11.885$, $\mathrm{df}=50, P=0.0026$ ), which was consistent with the results of Turner and Iverson [11], Fairbairn [30], and Reich et al. [14], that is, hormone level in an animal influencing its aggressiveness.

The experimental results showed that the aggression level of dispersers was significantly lower than that of residents, which agreed with the results of Fairbairn [30] but differed from that observed in the beach vole (Microtus breweri) [14], a species related to the root vole. In a wild beach vole population, dispersers and residents exhibited similar aggressive behavior patterns. The cause of this phenomenon might be that beach vole dispersers were a random sample of the resident population in terms of sex ratio and age structure, whereas in our study and the findings of Fairbairn [30], almost all dispersers were subadults, which were subordinate individuals in the population. Subordinate males were less aggressive and they disperse in response to social pressure during the breeding season [30].

To summarize, external environmental factors such as predation and food treatment, as well as internal conditions such as body weight and reproductive activity, were more important than density and gender in determining aggression levels of root vole populations.

\section{Acknowledgments}

The authors wish to express their sincere appreciation to Dr. Jianping Su, Dr. Meicai Wei, Dr. Wei Liu, and Mr. Yuming $\mathrm{Li}$ for their help in the course of field experiment and data analysis and to Dr. Ben Bravery for his help in paper 
editing. The research is completed under the financial support of the National Natural Science Foundation no. 3870345 and 30270242 and the Central South Forestry University Foundation for the Introduction of High-Level-Talents no. 101-0630.

\section{References}

[1] V. C. Wynn-Edwards, Animal Dispersion in Relation To Social Behavior, Oliver and Boyd, London, UK, 1962.

[2] R. M. F. Sadleir, “The relationship between agonistic behavior and population changes in the deermouse, Peromyscus maniculatus (Wagner)," Journal of Animal Ecology, vol. 34, no. 2, pp. 331-352, 1965.

[3] M. C. Healey, "Aggression and self-regulation of population size in deer mice," Ecology, vol. 48, no. 3, pp. 377-392, 1967.

[4] C. J. Krebs, B. L. Keller, and R. H. Tamarin, “Microtus population biology: demographic changes in fluctuating populations of $M$. ochrogaster and M. pennsylvanicus," Ecology, vol. 50, no. 4, pp. 587-607, 1969.

[5] C. J. Krebs, "Microtus population biology: behavioral changes associated with the population cycle in $M$. ochrogaster and $M$. pennsylvanicus," Ecology, vol. 51, no. 1, pp. 34-52, 1970.

[6] B. L. Keller and C. J. Krebs, "Microtus population biology: III Reproductive changes in fluctuating populations of $M$. ochrogaster and M. pennsylvanicus in southern Indiana, 196567," Ecological Monographs, vol. 40, no. 3, pp. 263-294, 1970.

[7] W. H. Conley, Behavior, demography and competition in Microtus longicaudus and M. mexicanus [Ph.D. thesis], Texas Tech University, Lubbock, Tex, USA, 1971.

[8] W. H. Conley, "Competition between Microtus: a behavioral hypothesis," Ecology, vol. 57, no. 2, pp. 224-237, 1976.

[9] J. R. Vale, C. A. Vale, and J. P. Harley, "Interaction of genotype and population number with regard to aggressive behavior, social grooming and adrenal and gonadal weight in male mice," Communications in Behavioral Biology, vol. 6, no. 2, pp. 209-221, 1971.

[10] W. Z. Jr. Lidicker, "Regulation of numbers in small mammal populations-Historical reflections and a synthesis," in Populations of Small Mammals Under Natural Conditions, vol. 5, pp. 122-141, PymatunIng Laboratory of Ecology, University of Pittsburgh, Pittsburgh, Pa, USA, 1978.

[11] B. N. Turner and S. L. Iverson, "The annual cycle of aggression in male Microtus pennsylvanicus and its relation to population parameters," Ecology, vol. 54, no. 5, pp. 967-981, 1973.

[12] J. E. Hofmann, L. L. Getz, and B. J. Klatt, "Levels of male aggressiveness in fluctuating population of Microtus ochrogaster and Microtus pennsylvanicus," Canadian Journal of Zoology, vol. 60, no. 5, pp. 898-912, 1982.

[13] J. E. Hofmann and L. L. Getz, "Levels of female aggressiveness in fluctuating populations of Microtus ochrogaster and $M$. pennsylvanicus," Acta Theriologica Sinica, vol. 24, no. 2, pp. 125131, 2004.

[14] L. M. Reich, K. M. Wood, B. E. Rothstein, and R. H. Tamarin, "Aggressive behaviour of male Microtus breweri and its demographic implications," Animal Behaviour, vol. 30, no. 1, pp. 117$122,1982$.

[15] S. Mihok, "Chitty's hypothesis and behavior in subarctic redback voles, Clethrionomys gapperi," Oikos, vol. 36, no. 3, pp. 281295, 1981.
[16] M. J. Taitt and C. J. Krebs, "Manipulation of female behaviour in field populations of Microtus townsendii," Journal of Animal Ecology, vol. 51, no. 2, pp. 681-690, 1982.

[17] J. M. Smith and G. R. Price, "The logic of animal conflict," Nature, vol. 246, no. 5427, pp. 15-18, 1973.

[18] E. S. Adams and M. Mesterton-Gibbons, "Animal contests as evolutionary games," American Scientist, vol. 86, no. 4, pp. 334341, 1998.

[19] H. Nie and J. Liu, "Regulation of root vole population dynamics by food supply and predation: a two-factor experiment," Oikos, vol. 109, no. 2, pp. 387-395, 2005.

[20] W. Xia, Alpine Meadow Ecosystem, Gansu People’s Publishing House, Lanzhou, China, 1982.

[21] J. Liu, X. Wang, and W. Liu, "Studies on the nutritional ecology of small herbivorous mammals: patterns of food selection and resource utilization for root voles and Gansu pikas," in Alpine Meadow Ecosystem, Fasc. 3, pp. 111-124, Science Press, Beijing, China, 1991, (Chinese).

[22] L. J. Liu, S. Su, L. W. Liu, W. X. Wang, N. H. Nie, and L. Y. $\mathrm{Li}$, "Field experimental studies on the multifactorial hypothesis of population system regulation for small rodents: an analysis of effects of food availability and predation on population dynamics of root vole," Acta Theriologica Sinica, vol. 14, no. 2, pp. 117-129, 1994 (Chinese).

[23] J. Liang, J. Zeng, Z. Wang, and Y. Han, "Study on the growth and development of root voles," Acta Plateau Biology Sinica, vol. 1, no. 2, pp. 195-206, 1982.

[24] D. L. Otis, K. P. Burnham, G. C. White, and D. R. Anderson, "Statistical inference from capture data on closed animal populations," Wildlife Monographs, vol. 62, no. 1, pp. 1-135, 1978.

[25] J. L. Smart, "Undernutrition and aggression," in Multidisciplinary Approaches To Aggression Research, pp. 179-191, Amsterdam Elsevier, North-Holland Biomedical Press, Amsterdam, The Netherlands, 1981.

[26] M. J. Taitt and C. J. Krebs, "Population dynamics and cycles," in Biology of New World Microtus, pp. 567-620, The American Society of Mammalogists, Shippensburg, Pa, USA, 1985.

[27] E. A. Desy, G. O. Batzli, and J. Liu, "Effects of food and predation on behaviour of prairie voles: a field experiment," Oikos, vol. 58, no. 2, pp. 159-168, 1990.

[28] G. A. Parker, "Evolutionarily Stable Strategies," in Behavioural Ecology: An Evolutionary Approach, pp. 30-61, Sinauer Associates, Sunderland, Mass, USA, 1984.

[29] D. W. Lendrem, Modeling in Behavior Ecology: An Introductory Text, Columbia University Press, New York, NY, USA, 1984.

[30] D. J. Fairbairn, "Behaviour of dispersing deer mice (Peromyscus maniculatus)," Behavioral Ecology and Sociobiology, vol. 3, no. 3, pp. 265-282, 1978. 

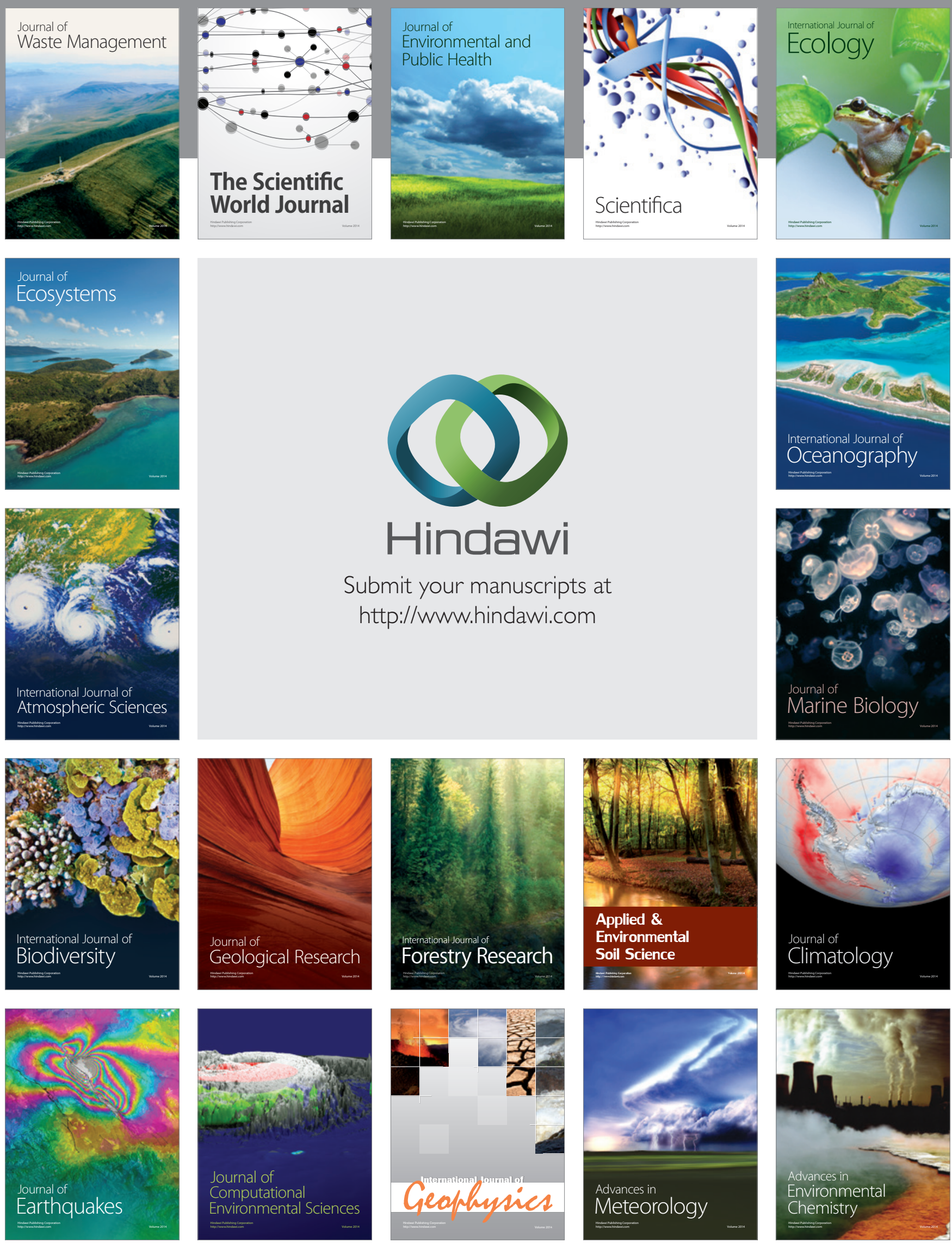